\title{
COMMENTARY
}

\section{BREXIT AND THE UK OIL \& GAS SECTOR}

\author{
John C LaMaster and Marc Hammerson*
}

\begin{abstract}
On 23 June 2016, the UK electorate voted in a referendum to leave the European Union (EU). This outcome is expected to have far-reaching consequences for UK industry, including the oil \& gas sector. These include: short- to medium-term uncertainty; potential changes to legislation affecting the downstream industry; restrictions on the free movement of goods and people; effects on the gas market; and renewed impetus for Scottish independence. It is impossible at this early stage to reach any definitive conclusions regarding the consequences of Brexit to the UK oil $\&$ gas industry, but this short article will discuss certain issues that are likely to be of interest and relevance.
\end{abstract}

\section{SHORT- TO MEDIUM-TERM UNCERTAINTY}

The referendum is advisory only, and there is no immediate change to the legal or regulatory regime governing the UK oil \& gas industry. The formal withdrawal process will commence only upon the delivery by the UK of a notice under Article 50 of the Treaty of the European Union. The Treaty, however, does not require the UK to deliver notice within any specified time period, or at all, and the EU cannot compel the UK to do so.

The short- to medium-term consequence of the referendum will create a high level of political, economic, social, commercial and legal uncertainty. This includes: when (if at all) the UK will deliver the Article 50 notice and commence the formal withdrawal process; what will be the nature of the new relationship to be negotiated between the UK and the EU;

\footnotetext{
* John C LaMaster, Partner, Akin Gump Strauss Hauer \& Feld LLP. Email: jlamaster@akingump.com. Marc Hammerson, Partner, Akin Gump Strauss Hauer \& Feld LLP. E-mail: mhammerson@akingump.com. This article first appeared in Legal Brexit published by Chambers and Partners in October 2016. It is reproduced with permission.

http://practiceguides.chambersandpartners.com/practice-guides/legal-brexit
} 
will Brexit lead to similar instability in other EU member states; and will Brexit lead to a second referendum on Scottish independence? It may take years to answer these questions.

In the meantime, this uncertainty is expected to have several consequences for the UK oil \& gas industry. The global oil \& gas industry has historically been cyclical in nature, and therefore industry participants are somewhat used to dealing with uncertainty. Brexit, however, is a unique historical event, without any direct precedent to give the oil \& gas industry any guidance as to what to expect.

It is anticipated that investment expenditure in the UK continental shelf (UKCS) may suffer as industry participants wait for this uncertainty to be resolved. This could stop investment in new exploration and delay projects that are already planned. Such additional negative business sentiment comes at a time of a record decline in the level of expenditure in the UKCS as a result of a low oil \& gas price environment. Current investment in the UKCS is about one-eighth of its peak.

It is also anticipated that the uncertainty arising from Brexit could have a negative effect on merger and acquisition (M\&A) activity in the oil \& gas industry. The M\&A market in UKCS assets has been relatively quiet for a while, given the low oil \& gas price environment and an unwillingness by buyers to assume decommissioning liabilities associated with aging infrastructure in a mature basin. An inactive M\&A market leaves assets in the hands of reluctant owners. One consequence of this is that investment in the UKCS will decline at a faster rate. Moreover, without an aggregate level of investment that sustains a critical mass of common-use infrastructure currently in place that can be utilized by new fields, there is a danger that future discoveries become uneconomic to develop and potential reserves are left unexploited. In other words, lack of new investment may cause the UKCS to enter a self-perpetuating cycle of decline.

In the months leading up to the referendum vote, the stabilisation of oil $\&$ gas prices, albeit at a relatively low level, had given rise to hopes that M\&A activity would pick up, as buyers and sellers had a firmer basis to negotiate and agree asset valuations. We wait to see whether the adverse impact on sentiment as a result of Brexit reverses, or merely delays, the expected uptick in M\&A activity resulting from stabilisation.

Markets do not like uncertainty, and an immediate consequence of Brexit was market volatility, with share prices, commodity prices and exchange rates all being affected. In particular, the pound fell to a 31-year low against the US dollar. This has both good and bad consequences for the UK oil \& gas industry. 
International oil markets are mostly priced in US dollars. As a result, oil producers in the UKCS who have revenues in dollars but a cost base paid for in pounds (such as oil companies with bases or operations in Aberdeen) will gain from the foreign exchange adjustment. However, those international participants that earn a significant portion of their revenues in pounds, such as those selling natural gas produced from the UKCS into the UK market, will find their profits devalued when pound revenue is converted into a domestic currency. In the global competition for oil industry capital, this makes the UK a less attractive environment for international investment. If the pound remains devalued then international companies may be less willing to fund new investments in the UKCS. Given its age and marginality, these foreign exchange consequences could have an adverse effect on the longevity of the UKCS. It will also increase the existing trend of UKCS assets being domestically owned by companies with their cost of capital priced in pounds, rather than dollars.

In the longer term, if the pound remains devalued, the UK overall, as a net importer of oil \& gas, will see higher wholesale energy prices. This will eventually trickle down to end-users. The issue of consumer energy costs and the prospect of price controls, which was debated during the 2015 general election campaign, may re-surface as an issue in the next scheduled general election in 2020. Any political reaction to higher consumer costs could result in a more interventionist approach being imposed on the UK's "Big 6" energy suppliers. A similar issue, but in respect of the adverse consequences to UK industry and manufacturing of high energy prices, is discussed below.

\section{OIL \& GAS LEGISLATION}

From a legislative standpoint, the immediate impact of Brexit on the UK oil \& gas industry is expected to be minimal. Despite the referendum, the UK is still in the EU, at least until the UK delivers the Article 50 notice to commence the formal withdrawal process and the mandatory two-year negotiation period is completed. As a result, there is no immediate change to the legal or regulatory regime applicable to the UK oil \& gas industry.

Even when such negotiation period ends, the legislative regime governing upstream UK oil \& gas is unlikely to change. Most laws derive from domestic policies, such as the current Petroleum Act, and international agreements to which the UK is a party, such as the United Nations Convention on the Law of the Sea. The taxation, licensing and regulatory regime for the upstream industry are all set by UK law and will not change as a result of Brexit. EU law does not have a significant effect on the upstream industry, other than through laws of general application such as 
competition, environmental and employment. Any changes in UK upstream are far more likely to result from a leave vote in any Scottish independence referendum. In this regard, the political division created between Scotland and England as a result of the different voting patterns on the EU between the two countries may, in the future, have indirect consequences for the upstream industry. This is discussed below.

There could, in contrast, be greater medium-term impact on the downstream oil \& gas sector. The UK is a net importer of gas and refined oil, with significant amounts coming from the EU and Norway. The UK also exports oil products to the EU. The two-way nature of these flows makes it essential that arrangements are put in place that avoid tariffs on energy. This outcome will depend on whether the UK negotiates to remain in the Single Market or, if this is not the case, the negotiated position between the UK and EU relating to tariffs on trade in energy. Any agreement that allows tariffs or other barriers on the trade in energy is likely to have significant consequences for both the UK and EU.

If Brexit results in the removal of EU competition laws, then the UK may have some leeway to promulgate laws and regulations that could benefit the downstream industry, such as allowing additional state support of industry during periods of oil price volatility. This could allow a government to take a more interventionist approach to energy and industrial policy. This could be promoted as both a benefit for consumers and also commercial users of energy (such as the UK's distressed steel industry which has pointed to high energy costs as one of the causes of its current distress).

In the longer term, if EU and UK laws begin to diverge in material respects, oil \& gas industry participants will have the additional cost and administrative burden of complying with two legal regimes. This could put the UK at a disadvantage in attracting new investment from European oil $\&$ gas companies, which are currently active participants in the UK's downstream sector.

Overall, the direct effect of Brexit on upstream is likely to be minimal and the effect on downstream will be felt, if at all, only over the mediumto long-term. Therefore we do not anticipate resulting regulatory changes will create a significant impact on the oil \& gas industry. In this respect, the industry should continue to enjoy a period of regulatory stability that should hopefully foster long-term investment in the industry. This benefit may be seen as a counter-weight to the other negative factors identified. 


\section{FREE MOVEMENT OF GOODS AND PEOPLE}

A fundamental principle of the EU's Single Market is the free movement of goods and people. European officials have stated that the UK will not be able to retain access to the Single Market unless it agrees to continue to permit the free movement of people. Restricting immigration was a fundamental plank in the Leave campaign's platform, so it is currently difficult to see how the UK can reconcile the political sentiment expressed by the electorate during the referendum campaign with the EU's fundamental principle that members of the Single Market must allow free movement of people.

The oil \& gas industry requires highly-skilled people and a flexible workforce that can be moved efficiently and quickly from project to project. The industry already has a skills shortage and a relatively aged workforce. It would be a burden to the industry if European expatriates could not work in the UK, and if UK expatriates could not work in the EU, without visas, work permits or other administrative restrictions. The burdens placed on industry will depend on whether the UK remains in the Single Market or, if not, the manner in which this issue is dealt with in the UK's exit terms.

Restrictions on the free movement of goods would likely manifest themselves as tariffs. This could affect the UK's imports of gas and of refined oil from the EU, as well as the UK's exports of oil products to the EU. If these are imposed this would have a significant effect on the UK's down- and midstream industries - not least because of the UK's reliance on imported natural gas.

\section{EFFECTS ON THE GAS MARKET}

The UK produces approximately $44 \%$ of its domestic gas requirements. As a result, the UK is a net importer of gas. It is anticipated that by 2020 the UK will import $70 \%$ of its gas requirements. The vast majority of imported gas is piped from Europe. A small proportion is shipped in the form of liquefied natural gas (LNG) and then re-gassified at a UK import terminal. The long-term result of Brexit may be to reduce the UK's reliance on piped gas from Europe and instead look to LNG supplies from the recently-opened United States export market (as well as other more traditional non-European shippers of LNG such as Qatar, Trinidad and Nigeria). LNG, like oil, is a tradable commodity which will be sold to whichever buyer offers the highest price net of indirect costs (such as tariffs). Historically, because (in part) of the trade in natural gas between the UK and Europe, there has been minimal pricing differences between the price at the UK's national balancing point (NBP) and European pricing 
points. However, if trade in natural gas between the UK and Europe is impeded and balancing between different European grids is impeded, future pricing differentials may emerge. The degree to which the UK moves away from the EU on trade in energy will determine the size of schism that may open up between the two markets. The degree to which the UK is able to negotiate tariff-free trade agreements with countries that supply LNG will determine the potential for the UK's further reliance on gas which is shipped rather than piped.

Brexit may also accelerate a move towards a different European pricing point for natural gas. The NBP gas trading hub is priced in pounds (with gas contracts traded in pence per therm). The Dutch TTF gas trading hub is a euro-denominated market (with gas contracts traded in euro/MWh). The NBP has traditionally had the highest liquidity in Europe. However, 2015 saw a change to the TTF having the highest liquidity. It seems that following Brexit the shift towards TTF will be accelerated, a trend that was already starting to develop in part due to the fact that the majority of gas trading in Europe is denominated in euros rather than pounds. For European companies without UK links, trading at the TTF can avoid additional currency risk exposure. The move by European traders away from NBP has occurred over recent years and looks set to continue.

\section{SECOND SCOTTISH INDEPENDENCE REFERENDUM}

Although the UK overall voted for Brexit, the majority in Scotland voted to remain in the EU. As a result, Nicola Sturgeon of the Scottish National Party (SNP) was quoted as saying that a second Scottish independence referendum was "highly likely" because it was "democratically unacceptable" that Scotland faced the prospect of being taken out of the EU against its will.

If the UK is broken up into its constituent countries, the majority of the UKCS's oil \& gas fields will fall within the exclusive economic zone belonging to Scotland. The uncertainty created by Brexit would be intensified by a second Scottish independence referendum. This would have several knock-on effects, including the likely dampening of further investment in, and M\&A activity involving, the UKCS.

An independent Scottish government is likely to take a more active approach to managing UKCS production. The SNP, a key proponent of independence and the current governing party in the Scottish parliament, has promised tax measures to improve exploration and investments and an active policy to ensure that premature cessation of production is avoided. At the same time, it is keen to promote an active industry in decommissioning dis-used infrastructure. 
It remains to be seen whether a second Scottish independence referendum is a realistic possibility. The last referendum resulted in a clear "remain" vote. Furthermore, the economics underlying the last referendum were based on an oil price of over $\$ 100$, and the SNP's plans for an independent nation with a Norwegian-style sovereign energy fund does not seem feasible in the current low oil \& gas price environment. Also, European officials so far have been cool at best to Scotland's suggestions that it wants to leave the UK and join the EU.

\section{CONCLUSION}

It is impossible at this early date to reach any definitive conclusions regarding the consequences of Brexit to the UK oil \& gas industry. The only certainty is that there will be uncertainty at least in the short and medium term. Hopefully we will look back in a few years and realise that leaving the EU has created a more prosperous and competitive UK oil \& gas industry. For the time-being, however, it is too early to say. 